\title{
IEM participa no Stage d'initiation au manuscrit médiéval
}

Catarina Barreira e Rita Carvalho

\section{(2) OpenEdition}

1 Journals

\section{Edição electrónica}

URL: http://journals.openedition.org/medievalista/665

DOI: 10.4000/medievalista.665

ISSN: 1646-740X

\section{Editora}

Instituto de Estudos Medievais - FCSH-UNL

\section{Refêrencia eletrónica}

Catarina Barreira e Rita Carvalho, «IEM participa no Stage d'initiation au manuscrit médiéval », Medievalista [Online], 9 | 2011, posto online no dia 02 janeiro 2011, consultado o 15 setembro 2020 URL : http://journals.openedition.org/medievalista/665

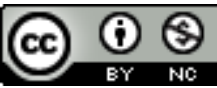

Mediavalista está licenciado com uma Licença Creative Commons - Atribuição-NãoComercial 4.0 Internacional. 
Titulo: IEM participa no Stage d'initiation au manuscrit médiéval Autor(es): Catarina Barreira e Rita Carvalho Enquadramento Institucional: Membros IEM, Faculdade de Ciências Sociais e Humanas, Universidade Nova de Lisboa.

Contacto: fernandesbarreira@gmail.com ritanou2004@yahoo.com.br Fonte: Medievalista [Em linha]. №9, (Dezembro 2010). Direc. José Mattoso. Lisboa: IEM. Disponível em: http://www2.fcsh.unl.pt/iem/medievalista/ ISSN: 1646-740X

\section{IEM participa no Stage d'initiation au manuscrit médiéval}

\section{Catarina Barreira e Rita Carvalho}

Decorreu no Institut de Recherche et d'Histoire des Textes (IRHT), Paris, entre os dias 4 e 8 de Outubro do presente ano, o Stage d'initiation au manuscrit médiéval. Este curso teve como principal objectivo dotar os participantes de ferramentas e de metodologias de trabalho no campo dos manuscritos medievais. Funciona como um complemento aos estudos universitários desenvolvidos pelos formandos (na sua maioria a realizar mestrados e doutoramentos), fornecendo elementos essenciais ao estudo 
aprofundado dos manuscritos da Idade Média, nas suas dimensões histórica, cultural, artística e mesmo arqueológica.

Nos dois primeiros dias, a estrutura do curso assentou na apresentação de diversas comunicações feitas por especialistas na área, e que abordaram aspectos como os percursores do livro medieval. No primeiro dia, as atenções foram dedicadas, após uma introdução geral ao curso, à caracterização do rolo de papiro em comparação com o códice, noções de codicologia (vocabulário, descrição técnica e física dos livros, suportes e materiais de escrita, a encadernação), a mise en page e ainda a mise en texte.

No dia seguinte, o curso começou com uma notável comunicação sobre a decoração dos manuscritos pela especialista Patricia Stirnemann, ao que se sucedeu uma palestra centrada no papel e contexto do incunábulo e livro impresso, entre a segunda metade do século XV e todo o século XVI. As sessões seguintes abordaram a história da escrita e problemas de paleografia, bem como os actuais recursos da Internet, culminando com uma comunicação sobre a importância das bibliotecas medievais para o conhecimento da história.

A partir do terceiro dia de curso, os participantes foram divididos em grupos de trabalho, em função do seu objecto de estudo e as sessões passaram a ter um carácter mais específico (no caso das formandas do IEM, o campo de trabalho foi o da Iluminura). Assim sendo, e para os códices iluminados, a abordagem foi iniciada na Biblioteca da École de Beaux Arts, com a especialista Patricia Stirnemann. Este atelier teórico-prático, para além do mérito de dotar os participantes do curso de conhecimentos que concernem às características pictóricas da imagem, à relação entre texto e imagem e ao papel da imagem no códice medieval, permitiu ainda o contacto entre os formandos e os próprios objectos (em depósito na Biblioteca), num âmbito cronológico que se estendeu do século XII ao século XVI, desde o rolo ao Livro de Horas, do Antifonário à Bíblia, com variedade pictórica e adaptada às características do próprio códice (da inicial monocromática à ornada e ainda à página integralmente decorada). Depois desta visita e já no período da tarde, numa sessão orientada por Patricia Stirnemann e Claudia Rabel, os participantes foram convidados a realizar vários exercícios práticos, de modo a aplicar e a desenvolver os conhecimentos adquiridos, em articulação com a pesquisa documental orientada. 
A manhã do dia seguinte centrou-se em apresentações feitas pelos formandos acerca dos trabalhos e projectos que se encontravam a desenvolver (e que estavam na origem da frequência do curso), o que decorreu num ambiente de grande informalidade, mas muito propício a um feed-back especializado. O período da tarde deste quarto dia de curso foi ocupado com uma visita guiada à biblioteca do IRHT e ao "laboratório", culminando com trabalho individual de pesquisa na biblioteca.

O último dia do curso centrou-se, no período da manhã, em exercícios de edição e de redacção de fichas descritivas de manuscritos e sua revisão crítica, cujos trabalhos ainda decorreram no âmbito das especificidades dos diversos grupos de trabalho. De tarde, após o preenchimento de um inquérito acerca da qualidade do curso, seguiu-se uma série de ateliers, de escolha livre, cujas temáticas andavam em torno dos assuntos tratados. Um dos ateliers escolhidos pelas formandas foi o "Mise en page e mise en texte des manuscrits grecs, hébreux, latins et des premiers imprimés" que promoveu uma série de exercícios para consolidação de conhecimentos, em ambiente de constante debate, tendo inclusivamente sido discutidas relações entre a mise en page medieval e o design gráfico contemporâneo.

Este curso, de cariz intensivo, forneceu aos participantes bases de trabalho fundamentais para o estudo dos manuscritos do período medieval, em particular no campo das metodologias de trabalho, na redacção de ficha descritiva de um códice, enfim, a tudo o que concerne ao campo de estudos que envolvam manuscritos, recorrendo a várias disciplinas e áreas do saber. Tudo isto são ferramentas significativas para os medievalistas que hoje trabalham de forma directa ou indirecta com os manuscritos. Outro aspecto a destacar é a organização e estruturação teórico-prática do curso que proporcionou aos formandos uma aplicação prática in loco dos conteúdos transmitidos.

Por tudo isto, e ainda pelo convívio e troca de impressões com pessoas de diversas áreas ligadas ao manuscrito (Literatura, Filologia, História da Arte, Música, entre outras) o curso revelou-se uma experiência extremamente enriquecedora, reforçada pela beleza outonal de uma Paris conturbada! 


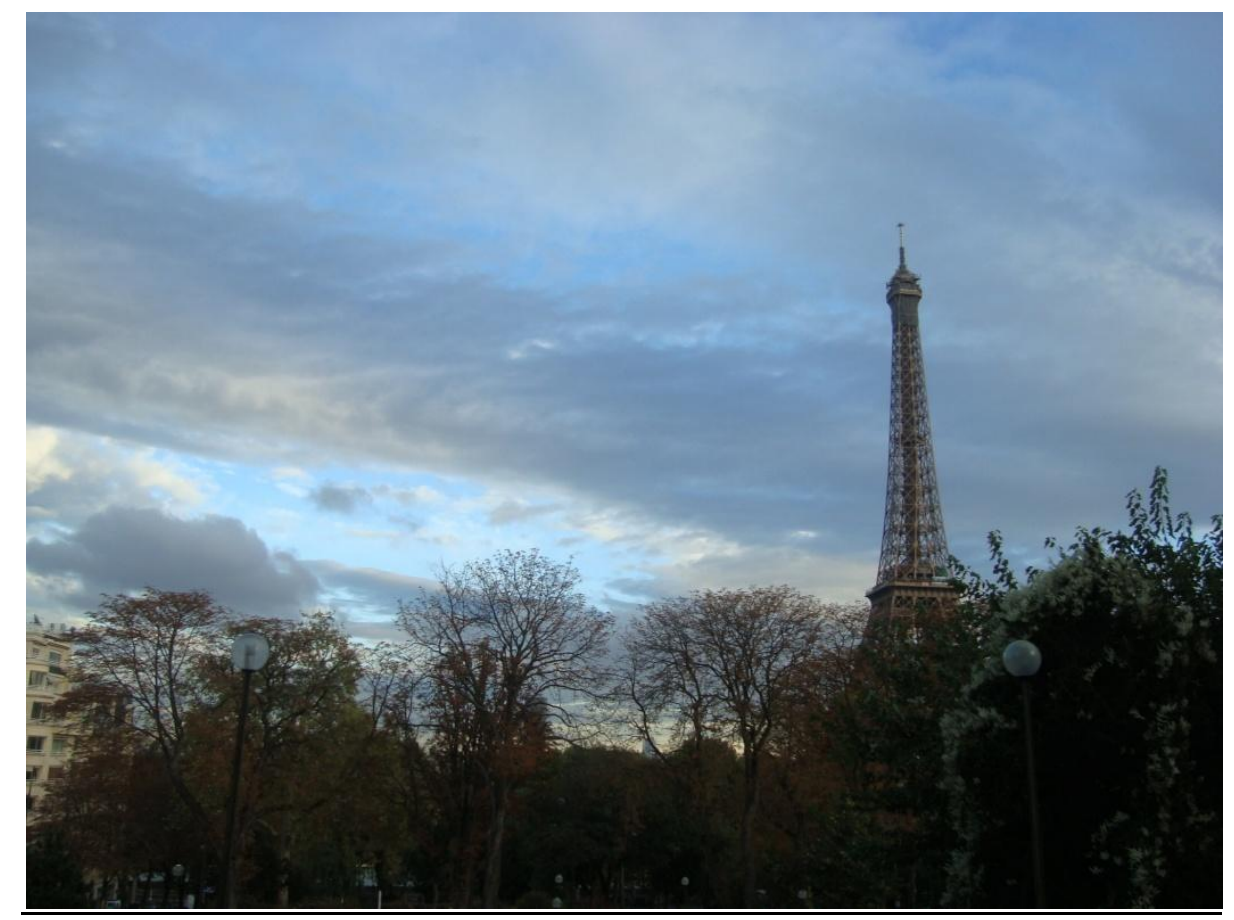

\section{COMO CITAR ESTE ARTIGO}

\section{Referência electrónica:}

BARREIRA, Catarina; CARVALHO, Rita - IEM participa no Stage d'initiation au manuscrit médiéval. Medievalista [Em linha]. N9, (Dezembro de 2010). [Consultado dd.mm.aaaa]. Disponível em

http://www2.fcsh.unl.pt/iem/medievalista/MEDIEVALISTA91barreiracarvalho9011.html.

ISSN 1646-740X.

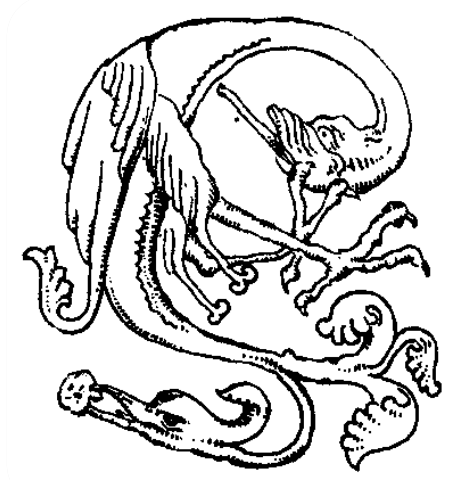

Medievalísta online $N^{\circ} 9 \mid$ Janeiro - Junho 2011 @ IEM - Instituto de Estudos Medievais 4 www2.fcsh.unl.pt/iem/medievalista 